\title{
Compreendendo a Aprendizagem da Mãe na Lida Com Seu Filho Num Centro de Terapia Intensiva Pediátrico
}

\author{
Márcia Siqueira de Andrade* \\ Centro Universitário da Fundação Instituto de Ensino para Osasco, Osasco, Brasil
}

\begin{abstract}
RESUMO
Este estudo foi delineado de forma qualitativa, e teve como objetivo desvendar como mães aprendem sobre a assistência prestada ao filho internado em centros de terapia intensiva pediátricos. Foi realizado em um hospital geral particular, da Região Sudeste do Brasil. Os dados foram colhidos por meio de entrevista semiestruturada com a mãe e observação participante. Os resultados demonstraram que a mãe aprende observando os profissionais de saúde e por meio das atividades desenvolvidas pela equipe multiprofissional. A mãe aprende a conviver e a compartilhar espaços limitados, tempos de atenção e dedicação ao filho e experiências de outros sobre como cuidar. A convivência educa a mãe e equipe multidisciplinar quando se compartilham crenças que permeiam as práticas cotidianas.
\end{abstract}

Palavras-chave: aprendizagem; hospitalização; família.

\section{ABSTRACT \\ Understanding the Mother's Learning in the Chore With the Son in a Pediatric Intensive Care Unit}

The objective of this qualitative study was to find out how mothers learn about caregiving to sons interned in pediatric intensive care units. It was carried out at a private hospital in the Southeast of Brazil. The data was collected through semi-structured interviews and participant observation. The results showed that the mother learns by observing the health professionals and through activities undertaken by the multiprofessional team. The mother learns to coexist and to share limited spaces; the periods to attend the son; and experiences of others about how to take care. The interaction educates the mother and the multidisciplinary team when they share beliefs ingrained in the daily activities.

Keywords: learning; hospitalization; family.

A hospitalização é um dos eventos que mais podem causar desconforto para o ser humano. No caso de crianças, a internação parece ser momento de desafios e de enfrentamentos, para ela e sua família, pois se afastam de seu meio habitual e "geralmente, passam por muitas situações ameaçadoras, desconhecidas, invasivas ou dolorosas" (Castelli, Lacerda, \& Carvalho, 1998, p. 139).

Os centros de terapia intensiva (CTIs) pediátricos surgiram da necessidade de aperfeiçoamento e concentração de recursos, para o atendimento a crianças em estado crítico de saúde e instabilidade de vida. Constituem-se de unidades hospitalares, com infraes- trutura especializada, que dispõem de assistências médica e de enfermagem ininterruptas, com equipamentos específicos próprios, recursos humanos qualificados e acesso a outras tecnologias diagnósticas e terapêuticas (Vila \& Rossi, 2002). O CTI pediátrico pode ser considerado um subsistema aberto, com características específicas, que faz parte de um conjunto de outros subsistemas, que conformam o sistema maior, denominado de instituição hospitalar. É aberto, na medida em que está em constante troca com os demais subsistemas e que se caracteriza por exigir ajustamentos emocionais e comportamentais de todas as pessoas envolvidas na sua rotina, como das pessoas que, de

\footnotetext{
Endereço para correspondência: Márcia Siqueira de Andrade, Centro Universitário da Fundação Instituto de Ensino para Osasco, Av. Franz Voegeli, 300, Vila Yara, Osasco, S,P CEP 06020-190. E-mail: mandrade@ unifieo.br.
} 
forma temporária, precisam desses espaços, seja como paciente ou acompanhante.

Considera-se que a metáfora que melhor define a dinâmica relacional, em uma UTI é "a ponte entre a vida e a morte", que sustenta o contexto comunicacional da mesma, deixando o CTI pediátrico de ser apenas um local, em termos espaciais, para se transformar em um contexto "gerador de significados" (Moré \& Macedo, 2006), em que a tensão, angústia e estresse estão sempre presentes como uma mensagem subliminar, afetando diretamente o processo de comunicação que ali acontece.

O propósito do presente trabalho foi realizar um estudo sobre a mãe que aprende a lidar com o filho doente em um CTI pediátrico, em situação de vulnerabilidade e de instabilidade de vida. $\mathrm{O}$ desejo de entender o aprendizado da mãe, construído no enfrentamento da internação de seu filho em um CTI pediátrico, apresentou-se na forma de inquietações, traduzidas nas seguintes questões: Quais são as dimensões desse processo? Será possível identificá-las e descrevê-las, considerando o olhar da mãe, em um CTI pediátrico? Tendo por referência o convívio da pesquisadora junto às crianças e suas famílias, seria possível captar o sentido atribuído por essa mãe à aprendizagem que se dá nesse contexto?

Uma iniciativa de pesquisa pressupõe interesse por um tema a ser investigado, interesse que se constrói a partir de experiências vividas. A escolha da temática para este estudo emergiu da experiência da pesquisadora como enfermeira no CTI pediátrico de um hospital particular, situado na Região Sudeste do Brasil. A lida diária, trabalhando como enfermeira nesse espaço de internação, trouxe a necessidade de reflexão sobre essa experiência. Objetivou-se, portanto, compreender como se dá o aprendizado da mãe na lida com seu filho, em situação de risco de vida.

\section{A MÃE E A HOSPITALIZAÇÃO DE UM FILHO}

Desde 1990, com o amparo da legislação brasileira, o Estatuto da Criança e do Adolescente, Lei $\mathrm{n}^{\circ}$ 8.069, determina, no seu Capítulo I, que: “Art. 12 - Os estabelecimentos de atendimentos à saúde deverão proporcionar condições para a permanência em tempo integral de um dos pais ou responsável, nos casos de internação de criança ou adolescente" (Lei 8.069, 1990).
A presença de um acompanhante durante a hospitalização da criança também defende a proteção integral, baseada no conhecimento de direitos específicos de todas as crianças e adolescentes, decorrentes da condição peculiar de pessoas em desenvolvimento, em consonância com a Convenção sobre os Direitos da Criança, adotada pela Assembléia Geral das Nações Unidas e promulgada pelo Decreto Presidencial 99.710, de 21.11.1990.

Nos últimos anos, por conta da legislação atual, a equipe multidisciplinar que atua em hospitais tem vivenciado mudanças na assistência à criança, com a presença da família, representada pela mãe ou outro familiar, como acompanhante. Para a família, a jornada da hospitalização da criança é difícil e desgastante, pois ambos compartilham angústias, preocupações e estresse, impondo a eles a reformulação de seu cotidiano, para estar com a criança hospitalizada, e sua rotina adaptada para manter a unidade familiar. Os profissionais envolvidos no contexto da criança hospitalizada, principalmente o enfermeiro ou enfermeira, devem procurar compreender a vivência da família e delinear intervenções que auxiliem durante a crise que pode representar a hospitalização da criança no seu ciclo vital.

A necessidade de hospitalização da criança gera sentimentos ambíguos à família, os quais podem estar relacionados ao sofrimento e a dor. É uma realidade distinta para a família, que passa a compartilhar a doença, o tratamento, os sucessos e insucessos, com outras famílias, ali presentes ou não, e com a equipe do hospital (Collet \& Oliveira, 2002). A hospitalização de uma criança é considerada um momento não previsível, onde há reorganização de papéis e, neste caso, a literatura destaca a mãe como representante principal da família, com a função de cuidadora da saúde de seus integrantes. Para Bezerra e Fraga (1996), a mesma torna-se alvo privilegiado dos problemas que o processo de internação suscita na instituição hospitalar, despertando os mais variados sentimentos, tais como impotência e angústia, decorrentes do quadro clínico e que afetam, também, diretamente, as relações familiares.

Especificamente, no CTI pediátrico, a mãe também aparece como a figura mais presente, no papel de cuidadora, cabendo mencionar que o próprio contexto do CTI pediátrico exige restrição de visitas e de acompanhantes, gerando afastamento de outros membros da família, do convívio do paciente (Nascimento, 2003). 


\section{Relações interpessoais: Mãe e equipe multidisciplinar}

As implicações das relações interpessoais, no espaço hospitalar, parecem profundas, pois podem ocorrer interferências internas, baseadas na constituição do sujeito, e, também, externas, vindas das instituições que afetam, de modo geral, a vida de quem adoece. A criança, ao ser admitida em um CTI pediátrico, depara-se, assim como sua família, com um ambiente já mitificado, hostil, repleto de equipamentos e uma equipe multidisciplinar que prioriza o tratamento físico. A criança é vista como fragmentos, onde só o pedaço físico importa; torna-se despersonalizada, transforma-se em um leito, um número, uma doença, um caso. Porém, cada criança possui uma identidade social, no seio de sua cultura (Batista, 2004).

A interrupção das rotinas cotidianas e do ambiente familiar, a presença de equipamento estranho e ameaçador, a necessidade de administrar tratamentos ou meios de diagnóstico assustadores e dolorosos, a necessidade de contatar com muitas pessoas, entre o pessoal técnico e auxiliar, e a impossibilidade de manter o controle sobre os acontecimentos são condições que dificilmente podem ser completamente eliminadas. A criança não fica alheia à percepção da gravidade da situação, diretamente ou através das reações dos pais e do próprio pessoal hospitalar, nem à necessidade de se confrontar com processos físicos estranhos, difíceis de compreender, dolorosos, e potencialmente limitadores da atividade habitual.

As famílias de pacientes internados que experimentam o vivenciar de uma doença crônica descobrem que o adoecer cronicamente desencadeia dificuldades relacionadas a condições estruturais, emocionais, envolvimento familiar no enfrentamento da doença, formação de redes familiares e sociais de apoio na busca de alternativa e facilitação no enfrentamento daquela situação (Silva, Guedes, Moreira, \& Souza, 2002). O maior impacto da admissão no CTI pediátrico, segundo Bennun (1999), é na identidade familiar, pois a família e o paciente perdem poder, autonomia e competência, tornando-se mais passivos e dependentes. Isto pode gerar grandes dificuldades, como a incerteza e o desespero diante da possibilidade de morte.

Quando o filho está hospitalizado, observa-se que a mãe busca aprender como lidar com o seu filho em ambiente diferente. Sentindo-se dependente de outras pessoas e para não perder seu lugar acompanha a equipe multidisciplinar, na demonstração de conhecimentos técnicos e científicos, assimilando-os, reunindo-os em novas bases de saber. Quando a hospitalização da criança se prolonga, a situação se torna ainda mais complexa e difícil, pois as reações da criança a essa intercorrência estão, de forma geral, associadas à cronificação da doença, e são influenciadas por diversos fatores, que incluem idade, desenvolvimento psíquico e gravidade da doença. À medida que o prognóstico da doença evolui, as exigências se acumulam, incluindo uma rotina circular de idas e vindas aos diversos setores do hospital, como quarto, centro cirúrgico, UTI e assim por diante. A equipe multidisciplinar necessita de sensibilidade para compreender que a fragilidade de saúde de uma criança, em um CTI pediátrico, pode enfraquecer e adoecer sua família; contudo, essa equipe também pode ser capaz de acolhê-la, de ensiná-la.

Dependendo das identificações que podem surgir entre o profissional, a criança e sua família, tornam-se frequentes as atitudes defensivas de incompreensão ou de mal-entendidos na comunicação, que mais traumatizam do que ajudam, pois durante a assistência hospitalar também é importante saber ouvir, visando a melhoria da criança e de sua família.

\section{MÉTODO}

\section{Participante}

Participou da pesquisa, a mãe de uma criança com 3 (três) meses de vida, esta admitida, no CTI pediátrico, com diagnóstico de leucemia. Além de primeira filha do casal, era, também a primeira neta por parte de ambas as famílias, materna e paterna.

\section{Instrumentos}

Neste estudo, utilizaram-se dois instrumentos de coleta de dados, concomitantes: a observação participante e o diário de campo. Os dados referentes ao perfil sociodemográfico foram coletados por meio de fonte secundária.

\section{Procedimento}

O projeto foi avaliado e aprovado por Comitê de Ética em Pesquisa. Foi solicitada uma declaração, para realização da pesquisa, sendo concedida a autorização para a sua implementação, no âmbito do hospi- 
tal. Atendendo à Resolução 196/96 (1996) do Conselho Nacional de Saúde, foi emitida uma carta, informando à participante sobre o tema e o objetivo do estudo, assegurando que as informações seriam tratadas anônima e sigilosamente e serviriam apenas para fins científicos. A participante assinou um Termo de Consentimento Livre e Esclarecido.

O trabalho de campo foi realizado durante o período de oito meses, de março a outubro, período de hospitalização da filha da participante da pesquisa, em um CTI pediátrico de instituição particular, localizada na Região Sudeste do Brasil. A observação participante e o seu registro foram norteados a partir dos seguintes aspectos: caracterização do cenário, sentimento da mãe, durante o período de internação da filha, capacidade da mãe de inteirar-se dos procedimentos utilizados pela equipe na manutenção da vida da filha.

O registro da observação foi feito no diário de campo. O diário de campo da pesquisadora constou de um caderno pautado e paginado, destinado ao registro das informações obtidas, por meio da observação participante. As anotações no diário de campo seguiram as orientações de Mayan (2001), sendo constituídas por relatos descritivos, onde foram registrados, objetivamente, os acontecimentos observados, no cenário do estudo.

O fato de a pesquisadora atuar como enfermeira no CTI pediátrico do hospital em pauta garantiu a capacidade para inteirar-se dos procedimentos utilizados pela equipe, bem como favoreceu a observação e a interação com a mãe/participante. Os momentos diários de atendimento à criança, durante os oito meses em que esta esteve hospitalizada, propiciaram diálogos entre a pesquisadora e a mãe, que parecia aproveitar a oportunidade para expor suas dúvidas, impressões e angústias. Com isso, os registros no diário de campo passaram a traduzir o resultado da relação pessoal que se estabeleceu entre pesquisadora e pesquisada, tornando-se valiosos para a consecução do objetivo da pesquisa.

Os registros no diário iniciaram-se com a inserção da pesquisadora no campo e terminaram com a conclusão do relatório final. Foram realizados imediatamente após as observações, indicando a data, a hora, o local e o período de observação, como recomendam Lüdke e André (2003).

\section{RESULTADOS E DISCUSSÃO}

Em um determinado período da hospitalização da criança em um CTI pediátrico, foi possível escutar da mãe investigada expectativas de como poderia cuidar do seu filho, com a participação da equipe. Parece demonstrar o medo de ser excluída da relação com a filha:

... eu posso permanecer ao lado da minha filhinha, neste momento... só eu... ou o pai também... eu gostaria que ele participasse também... ele trabalha... quase não nos vemos mais... quando ele vem, eu durmo um pouquinho..."

As doenças que exigem hospitalização podem desencadear uma crise e desintegração familiar (Bezerra \& Fraga, 1996; Santos, Campos, Dias, Cardoso, \& Oliveira, 2001), exigindo reorganização da família. Segundo Crepaldi (1999), "a doença e a internação provocam um estado de desorientação comparado ao da loucura" (Crepaldi, 1999, p. 111), obrigando a família à constatação da gravidade da doença.

Um aspecto comum a quase todas as famílias diz respeito à presença do pai, durante o período de internação, no CTI pediátrico. Na hospitalização, em outras unidades de internação, sabe-se que a mãe assume o papel de cuidadora principal (Bezerra \& Fraga, 1996; Centa, Moreira, \& Pinto, 2004), mesmo porque, ao pai, é delegada a função de continuar provendo recursos financeiros à família. Porém, no momento da entrada da criança no CTI pediátrico, o pai articula formas de não sair tão prejudicado em seu emprego ou atividade laboral, e faz questão de estar presente junto com sua esposa, no CTI pediátrico. Tal como a literatura destaca (Crepaldi, 1999), o pai aparece em momentos de crise.

Porém, Bousso e Ângelo (2003) identificaram que as famílias sofrem pressão social para o retorno às atividades laborais. Asted-Kurki, Lehti, Paunonen e Paavilainen (1999) referem que, a partir da hospitalização, os pais são forçados a deixar as atividades diárias e, diante da impossibilidade de dar continuidade nas atividades, os pais sentem-se muito ansiosos, agravando a situação daqueles que acompanham a criança na internação, no CTI pediátrico:

... nem sei mais como vai ficar minha vida depois daqui... acho que vou ter que procurar outro emprego... nem sei de mais nada... não sei mais de nada fora daqui... 
A mãe percebe que, com a hospitalização da filha, ocorrem lacunas no âmbito das relações e funções familiares, sendo necessário assumir vários papéis, visando minimizar esses espaços: esposa, mãe, trabalhadora, constituindo-se a pessoa central da família, neste momento (Bezerra \& Fraga, 1996). Para essas mães, estar no hospital significava, analogamente, estar em uma prisão, mesmo sabendo que nada as impedia de sair, quando sentissem necessidade. Essa ideia ultrapassava as paredes e o isolamento imposto pela situação, uma vez que a mãe sentia-se obrigada a estar ao lado de seu filho, deixando, muitas vezes, de atender às necessidades de outros filhos:

... nossa... quanta gente faz parte da equipe, vocês orientaram, mas eu não sabia que minha filhinha está tão protegida... mas e quando ela sair daqui, como será...

O depoimento revela que, após o primeiro impacto do internamento da filha no CTI pediátrico, e observando a evolução das condições de sua saúde, a mãe passa a reconhecer a necessidade de permanência da filha naquele setor. Mesmo identificando o ambiente como assustador, a mãe passa a ver a internação como algo positivo para a saúde de sua filha. Além disso, entende que os profissionais de saúde possuem capacidade técnica para desempenho de suas funções. Dessa forma, novos sentimentos afloram, como confiança e esperança. A mãe verbaliza que se sente protegida. A família busca cuidados especializados para "recuperar" a saúde da criança enferma, e encontra uma equipe multidisciplinar, em um ambiente com características próprias (equipamentos tecnológicos, avançados ou não; ambiente fechado, confinado, vigiado continuamente, por pessoas e por equipamentos; ambiente com controle de circulação da família, de visitas, e outros), que não é o seu local habitual, o seu domicílio. Neste encontro, a equipe e a família cuidam da criança, o que exige, por parte de todos, uma forma de negociação, de aproximação, de aprendizagem e até de acomodação dos cuidados.

Em uma pesquisa com mães de crianças internadas em CTIs pediátricos, Board e Ryan-Wenger (2002) relataram que este ambiente é considerado um grande estressor, e a maior dificuldade está relacionada com a presença de aparelhos de monitoração controlando a criança. Outro estressor significativo é ver as crianças com tubos, recebendo injeções. É o que parece demonstrar o depoimento da mãe:
... se puder colher o exame de sangue mais tarde, só antes de ela acordar naturalmente, eu prefiro que deixem para depois, o doutor... só ia passar mais tarde mesmo. tudo bem para vocês?... além disso, ela já está tão cheia de tubos e aparelhos que acho que dormiu de exaustão...

Para a mãe, é difícil ver sua filha ligada a fios e tubos, cercada de cuidados e aparelhos. Um fato significativo observado foi que a mãe, mesmo com todas as dificuldades de reconhecer o bebê doente como a filha esperada durante toda a gestação, sempre a via como uma pessoa, com sentimentos e individualidades, e era dessa forma que procurava se relacionar com ela, apesar de toda a impessoalidade do ambiente.

A insegurança e o medo referidos pela mãe podem estar atrelados ao desconhecimento acerca da unidade de internamento onde se encontra. Sentimentos semelhantes foram, também, apontados por mães cujos filhos encontravam-se na mesma condição (Ditts, Mota, \& Sena, 2008; Vasconcelos, Leite, \& Scochi, 2006). Nesses estudos, as mães revelaram que são vários os significados vivenciados por elas - quais sejam: angústia, ansiedade, preocupação, alegria, medo do desconhecido e das diversas situações experienciadas - dentre elas, separação da família durante a hospitalização, mudança de hábitos do dia-a-dia, separação do companheiro, dentre outros. Miles, Burchinal, Holditch-Davis, Brunsse e Wilson (2002) e Noyes (1998) destacam que o maior estresse está associado com a aparência das crianças, alteração na função parental e ambiente com muito barulho.

O medo, expresso nas falas da mãe, está associado a não sobrevivência da filha. A morte é um fato temido por todo ser humano, em especial pelos pais, que comumente não aceitam que seus filhos morram antes deles, pois estariam alterando a "ordem natural" do ciclo da vida. O CTI pediátrico é uma unidade complexa, onde sobreviver e morrer está no imaginário das famílias. Esse setor, apesar de necessário, leva os pais a um estado de insegurança, acirrada pela definição social atribuída a esse ambiente.

Observa-se que a tarefa do cuidado, no hospital, permanece centralizada na mãe, tornando-a quase representante exclusiva da família (Bezerra \& Fraga, 1996). A mãe passa a ser a pessoa mais presente, e tem o caráter de assumir a responsabilidade pela criança. Com isso, ela passa a vivenciar a situação com sentimentos de divisão e ambiguidade, descuidando-se de si e deixando de lado as atividades que realizava 
anteriormente à hospitalização (Bezerra \& Fraga, 1996). É o que se percebe no depoimento a seguir:

... depois que a gente é mãe, aprende a dar valor para muitas coisas, a gente vê o quanto uma mãe sofre por um filho, ela faz coisas por ele que talvez o pai não faça, por essa pequerrucha daria até minha vida, mas não posso, 'né' (sic)...

A observação participante possibilitou perceber que o processo de aprendizagem e de capacitação da mãe, para o cuidado com o filho internado, ocorre durante todo o tempo em que ela permanece na instituição. Lopes (2005) constatou, em seu estudo, que a permanência da mãe junto ao filho durante a internação no CTI neonatal possibilitou esse aprendizado com relação aos cuidados com o filho, sendo que o aprendizado se deu através de observação e, também, ao realizar algumas ações de cuidado, com a permissão da equipe de enfermagem. Segundo a autora, a maneira como as mães vivenciam o momento da internação hospitalar e o relacionamento estabelecido com a equipe assistencial tornam-se fundamentais para que isso ocorra. Esse achado foi analisado também por Melo (1998), que, ao realizar um estudo com o objetivo de apreender os cuidados domiciliares prestados à criança prematura e de baixo peso, no primeiro mês de vida, após alta hospitalar, constatou, nos relatos das mães, dois aspectos relevantes, relacionados ao período de hospitalização do bebê: o aprendizado para o cuidado com o filho e sentir-se confiante para o cuidado no domicílio.

\section{CONCLUSÃO}

Este estudo foi delineado de forma qualitativa, e o objetivo foi compreender como as mães aprendem sobre a assistência prestada ao filho internado em CTIs pediátricos. Nesta pesquisa, foram apresentadas narrativas de uma mãe, verbalizadas no dia-a-dia em um CTI pediátrico, no processo de aprender a cuidar do filho, em momento vulnerável. Os resultados deste estudo possibilitaram delinear que a mãe aprende sobre o cuidar do filho observando os profissionais de saúde, trocando experiências com outras mães que vivenciam a mesma situação e por meio das atividades desenvolvidas pela equipe multiprofissional. A mãe aprende a conviver e a compartilhar espaços limitados, tempos de atenção e de dedicação ao filho, experiências de outros em como cuidar, pegar no colo, etc. A convivência educa a mãe e a equipe multidiscipli- nar, quando se compartilham as crenças que permeiam as práticas cotidianas. Profissionais e familiares compõem grupos distintos, em relação ao grupo das crianças, e cada grupo é orientado por crenças que o levam a se empenhar em tarefas e/ou papéis sociais nos quais acreditam e que lhes são atribuídos.

Apontar dimensões educativas para a mãe que se apresenta no enfrentamento da doença de seu filho requer, também, o reconhecimento de que aprender, nesse contexto hospitalar, significa assumir a incerteza da cura. Atitudes são educativas, quando congruentes com as crenças que carregam. Atitudes são mais importantes que técnicas na viabilização da criação de sentidos. Apresentam-se no gesto: abraçar, tocar, sorrir, limpar a saliva que escorre pela face, pegar no colo, segurar a boneca ou o equipamento que auxilia na identificação e na sobrevida de seu filho.

A contribuição deste estudo acerca da aprendizagem de uma mãe em uma unidade hospitalar é a possibilidade de reflexão de todos que se encontram nesse contexto (enfermeiros, médicos, psicólogos, nutricionistas, assistentes sociais, voluntários, funcionários administrativos, família, doente), sobre a importância das crenças de cada um. Para a família, a jornada da hospitalização da criança é difícil e desgastante, pois família e criança compartilham angústias, preocupações e estresse, impondo à família a reformulação de seu cotidiano para estar com a criança hospitalizada, e sua rotina, adaptada para manter a unidade familiar. Promover o desenvolvimento sadio, pleno e harmonioso da criança com sua mãe durante a hospitalização requer, necessariamente, garantir condições adequadas de desenvolvimento e aprendizagem, durante este período.

\section{REFERÊNCIAS}

Asted-Kurki, P., Lehti, K., Paunonen, M., \& Paavilainen, E. (1999). Family member as a hospital patient: Sentiments and functioning of the family. International Journal of Nursing Practice, 5, 155-163.

Batista, M. A. (2004). Presença do sagrado em um momento crítico: Internação em uma unidade de terapia intensiva. Revista Brasileira de Enfermagem, 57, 579-585.

Bennun, I. (1999). Intensive care units: A systemic perspective. Journal of Family Therapy, 21, 96-112.

Bezerra, L. F. R., \& Fraga, M. N. O. (1996). Acompanhar um filho hospitalizado: Compreendendo a vivência da mãe. Revista Brasileira de Enfermagem, 49, 611-624.

Board, R., \& Ryan-Wenger, N. (2002). Long-term effects of pediatric intensive care unit hospitalization on family with young children. Heart \& Lung, 31, 53-66. 
Bousso, R. S., \& Angelo, M. (2003). The family in the intensive care unit: Living the possibility of losing a child. Journal of Family Nursing, 9, 212-221.

Castelli, M., Lacerda, D. P. D., \& Carvalho, M. H. R. (1998). Enfermagem no CTIP: A criança, a família e a enfermeira enfrentando situações difíceis. São Paulo: Roca.

Centa, M. L., Moreira, E. C., \& Pinto, M. N. G. H. R. (2004). A experiência vivida pelas famílias de crianças hospitalizadas em uma unidade de terapia intensiva neonatal. Texto Contexto Enfermagem, 13, 444-451.

Collet, N., \& Oliveira, B. (2002). Enfermagem pediátrica. Goiânia: $\mathrm{AB}$.

Crepaldi, M. A. (1999). Hospitalização na infância: Representações sociais da família sobre a doença e a hospitalização dos filhos. São Paulo: Cabral.

Decreto n. 99.710. (1990, 21 de novembro). Promulga a Convenção sobre os Direitos da Criança. Brasília, DF: Presidência da República. Retirado de http://www.planalto.gov.br/ccivil_03/ decreto/1990-1994/D99710.htm

Ditts, E. S., Mota, J. A. C., \& Sena, R. R. (2008). O cotidiano no alojamento conjunto, das mães de crianças internadas em uma UTI de terapia intensiva e neonatal. Revista Brasileira de Saúde Materno Infantil, 8, 75-81.

Lei n. 8.069, de 13 de julho de 1990. (1990). Dispõe sobre o Estatuto da Criança e do Adolescente e dá outras providências. Brasília, DF. Retirado de http://www.planalto.gov.br/ccivil_03/ Leis/ L8069.htm

Lopes, T. C. (2005). Programa de internação domiciliar neonatal: Espaço para a construção da autonomia no cuidado materno com a criança. Dissertação de mestrado não-publicada, Universidade Federal de Minas Gerais, Belo Horizonte.

Lüdke, M., \& André, M. D. E. (2003). Pesquisa em educação: Abordagens qualitativas. São Paulo: EPU.

Mayan, M. (2001). Una introdución a los métodos cualitativos: Modulo de entrenamento para estudiantes y profesionales. International Institute for Qualitative Methodology. Retirado de http://www.ualberta.ca/ iiqm/pdfs/introduccion.pdf

Melo, D. F. (1998). O cuidado de enfermagem no seguimento de crianças prematuras e de baixo peso. Tese de doutorado nãopublicada, Universidade de São Paulo, Ribeirão Preto.
Miles, M. S., Burchinal, P., Holditch-Davis, D., Brunsse, S., \& Wilson, S. M. (2002). Perceptions of stress, worry, and support in black and white mothers of hospitalized, medically fragile infants. Journal of Pediatric Nursing, 17, 82-88.

Moré, C. L. O. O., \& Macedo, R. S. M. (2006). A psicologia na comunidade: Uma proposta de intervenção. São Paulo: Casa do Psicólogo.

Nascimento, E. R. P. (2003). Acolhimento no espaço das relações na UTI. Tese de doutorado não-publicada, Universidade Federal de Santa Catarina, Florianópolis.

Noyes, J. (1998). A critique of studies exploring the experiences and needs of parents of children admitted to pediatric intensive care units. Journal of Advanced Nursing, 28, 134-141.

Resolução n. 196, de 10 de outubro de 1996 (1996). Ministério da Saúde, Conselho Nacional de Saúde, Comitê Nacional de Ética em Pesquisa em Seres Humanos. Diretrizes e normas regulamentadoras de pesquisa envolvendo seres humanos. Brasília, DF. Retirado de http://conselho.saude.gov.br/resolucoes/1996/ Reso196.doc

Santos, A. F., Campos, M. A., Dias, S. F. P., Cardoso, T. V. M., \& Oliveira, I. C. S. (2001). O cotidiano da mãe com seu filho hospitalizado: Uma contribuição para a enfermagem pediátrica. Escola Anna Nery Revista de Enfermagem, 5, 325-334.

Silva, L. F., Guedes, V. C. E. Moreira, R. P., \& Souza, A. C. C. (2002). Doença crônica: O enfrentamento pela família. Acta Paulista de Enfermagem, 15, 40-47.

Vasconcelos, M. G. L., Leite, A. M., \& Scochi, C. G. (2006). Significados atribuídos à vivência materna como acompanhante do recém-nascido pré-termo e de baixo peso. Revista Brasileira de Saúde Materno Infantil, 6, 47-57.

Vila, V. S. C., \& Rossi, L. A. (2002). O significado cultural do cuidado humanizado em unidade de terapia intensiva: Muito falado e pouco vivido. Revista Latino-Americana de Enfermagem, 10, 137-144.
Recebido: 30/11/2009

Última revisão: 28/09/2010

Aceite final: 04/11/2011 